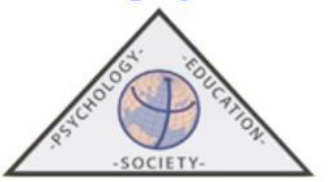

\title{
Attitudes towards people with mental illness among medical students: A qualitative research
}

\author{
Matías E. Rodríguez-Rivas ${ }^{1,2}$ \\ ${ }^{1}$ Universidad del Desarrollo, Chile \\ ${ }^{2}$ Universidad de Almería, España \\ Recibido el 22 de junio de 2020. Aceptado el 18 de diciembre de 2020
}

\begin{abstract}
Psychiatric illnesses affect more than 450 million people worldwide, with several consequences for those who are affected, along with the presence of high numbers of discrimination, stigmatization, and negative attitudes of the general population. These negative attitudes have been observed even in health professionals, negatively impacting on the quality of care, adherence to treatment and well-being of affected users. This study describes attitudes of medical students towards people with psychiatric illness from a qualitative perspective, through the analysis of thematic content of 12 semi-structured interviews conducted with first- to fourth-year medical students. Among the results, a diversity of identified attitudes outstands, including empathy, frustration, indifference and rejection, uncertainty and fear, tolerance and social acceptance. As a discussion, it is stated that most of the findings were consistent with the international literature, however there are new findings that are not described, highlighting the attitude of fear of being harmed and the rejection towards people with psychiatric pathologies. The design and implementation of educative interventions that facilitate contact with users, in order to reduce stigma and negative attitudes in future medical professionals, is concluded as an urgent challenge. Finally, it is proposed for future research to develop longitudinal and comparative studies that consider measuring the effectiveness of these interventions.
\end{abstract}

Keywords: Stigma; Undergraduate Students; Mental Health; Medical Education.

Actitudes hacia las personas con enfermedad mental en estudiantes de medicina: Un estudio

cualitativo

RESUMEN: Las enfermedades psiquiátricas afectan a más de 450 millones de personas a nivel mundial, con diversas consecuencias en quienes las padecen, junto con la presencia de altas cifras de discriminación, estigmatización y actitudes negativas de la población. Estas actitudes negativas se han observado incluso en profesionales de la salud, impactando negativamente en la calidad del cuidado, adherencia al tratamiento y bienestar de los usuarios afectados. El presente estudio describe las actitudes de estudiantes de medicina hacia las personas con enfermedades psiquiátricas desde una perspectiva cualitativa, mediante el análisis de contenido temático de 12 entrevistas semiestructuradas realizadas a estudiantes de primer a cuarto año de la carrera de medicina. Dentro de los resultados destaca una diversidad de actitudes identificadas, entre ellas, la actitud empática, frustración, indiferencia y rechazo, incertidumbre y miedo, tolerancia y aceptación social. Como discusión se plantea que gran parte de los hallazgos fueron concordantes con la literatura internacional, no obstante, existen nuevos hallazgos que no se encuentran descritos, destacando la actitud de miedo a ser dañados y el rechazo hacia los usuarios con patologías psiquiátricas. Se concluye como desafío urgente el diseño e implementación de intervenciones educativas que faciliten el contacto con usuarios, con el fin de disminuir el estigma y actitudes negativas en futuros profesionales médicos. Finalmente se plantea para futuras investigaciones el desarrollar estudios longitudinales y comparativos que midan la eficacia de estas intervenciones.

Palabras clave: Estigma; Estudiantes Universitarios; Salud Mental; Educación Médica.

Correspondencia: Matías E. Rodríguez-Rivas. Avda. Plaza 680, Chile. E-mail: matrodriguezr@udd.cl 


\section{Introduction}

It has been described that there are about 450 million people internationally affected by a mental or behavioral disorder, and it is the cause of more than $33 \%$ of the overall burden of diseases, which represents an increase of 18\% from the year 2005 to 2015 (Pan American Health Organization, 2016). At the national level and when compared to other countries in the Americas, Chile leads in the prevalence and incidence of mental illness with $23.2 \%$ of the national population affected, which means that only in the Metropolitan Region about 2 million people have some mental pathology (Vicente et al., 2016), generating a direct, but as well an indirect impact in population's well-being and in the country's productivity (Trautmann et al., 2016).

Within the consequences associated to the presence of mental disorder, it has been described that affected people has a lower life quality and life expectancy, along with an increase of problems in physical health and premature mortality rates, since the probability of suffering a premature death increases between 40 and $60 \%$ due to health problems related to cancer, cardiovascular or communicable disease, and frequently suicide (Too et al., 2019). Those pathologies in turn are associated to high levels of discrimination and negative stigmas from the population, which leads to attitudes and behaviors that have a direct impact on affected people and in the request for professional help from the general population, causing a delay of 15 to 25 years the consultation of mental health services (Ostrow et al., 2014). In this respect, it has been described that the stigma, discrimination, and negative attitudes from the general population and healthcare professionals toward people affected by mental illness represent a stressor that reduces the life quality and the possibility of seeking a treatment, and at the same time a notoriously increase in non-compliance with therapeutic recommendations in patients affected by these pathologies (Corrigan \& Watson, 2002).

\section{Attitude towards people affected by a mental illness}

An attitude is an organized predisposition to think, feel, perceive, and behave in a certain way in the presence of a referent or a cognitive object, being a steady structure of beliefs that influence someone to behave in a selective way facing attitudinal referents, in this case towards people affected by mental illnesses (Salve et al., 2013). In combination with this, the way in which perception, beliefs, opinions, and attitudes towards this people are determined to a large extent by the social group patterns of the population (Björkman et al., 2008). These patterns are mold by the socialization process, stablishing relations that promote or inhibit the value, perceptions, and particular concepts formation, which conforms as of negative values that lead to stigmatization, discrimination, and stablishing negative attitudes towards certain people or social group, including those affected by some mental pathology (Ellemers et al., 2002). Thus, the attitude and behave towards people affected by mental illness are expressed through disdain, prejudice, and discrimination (Ebrahimi et al., 2012).

Evidence shows that people affected by mental illness are one of the most vulnerable populations, since they frequently find themselves with discriminatory attitudes from general population and healthcare professionals, which tends to restrict their rights and generate inequality in the access, treatment, and results in health (Poreddi et al., 2017). As a consequence of these prejudices, discriminatory acts and attitudes towards people with psychiatric pathologies, people frequently present a low self-esteem and a lower quality of life, moreover a low treatment adherence and a significant reduction in their social networks (Corrigan et al., 2013).

It is been also observed that, usually, these people cannot access to a standardized job or educational position, in addition present difficulty to stablish friendly or couple's relationship (Howard et al., 2009). Therefore, it becomes a counterproductive phenomenon to achieve full social inclusion of 
individuals with some mental disorder, in addition to interfere in the seeking and maintenance of employment, inability to continue or finish studies, achievement of technical or professional goals, possession of an adequate housing, in combination with lack of social support, low self-esteem, and increased risk of suicide (Yang et al., 2013).

These negative attitudes have been observed even in mental health professionals such as physician, psychiatrists, psychologists, and nurses (Wahl \& Aroesty-Cohen, 2010). In this connection, research shows that more than $40 \%$ of people affected by a mental disorder affirm an unfair treatment at least in one occasion in health services (Funk et al., 2012), which negatively impacts in the quality of care provided by the medical team to patients affected by any disease from the mental health spectrum (Schulze, 2007).

\section{Attitude from health professionals and students towards people affected by a mental illness}

Several studies have shown that health professionals are not the exception in having a negative attitude towards people with psychiatric diseases, even those dedicated to mental health show negative attitude towards these patients (Arens et al., 2019). The attitudes and knowledges of these professionals have been indicated as the major determinants in the quality and results of the mental health care, basically, because they directly affect in the treatment, communication, resource allocation, and quality of care provided, being of lower quality on professionals with deficient attitudes and knowledges in the area (Jadhav et al., 2007).

International studies carried out on medical students show that their attitude possesses negative results towards social treatment and reinstatement of people affected by mental illness compared to nursing students (Poreddi et al., 2014). In conjunction with this, it has been seen that there are higher tolerance, benevolence, and optimism rate in medical students under 20 years old, which has been observed to decrease as age increases (Ewalds-Kvist et al., 2013). By analyzing the differences in the attitude towards people with mental pathologies, it has been seen that medical students stablish patient categories, showing less empathy towards those are affected by a psychiatric disease compared to other users (Desai \& Chavda, 2018). Nevertheless, studies reveal that the students who were familiarized with people affected by mental pathologies have less restrictive and more benevolent attitudes towards this population (Anagnostopoulos \& Hantzi, 2011).

On the other hand, when there is training in the knowledge and belief acquisition that improves the recognition, handling, and prevention of mental illness a reduction of these discriminatory attitudes towards people with mental disorders is generated, which in turn is associated to a minor gap in the treatment and in a better quality of life for the patients and their families (Lam et al., 2010). In a similar vein, it has been seen in health professionals a positive attitude boosted when there is experience in psychiatric services for more than a month (Hsiao et al., 2015), also presenting minor indicators of restrictive attitudes and major benevolent attitudes when a link and contact with users affected by a mental pathology are stablished (Corrigan \& Wassel, 2008), particularly in those who have a family member or close friend with this diagnosis (Yuan et al., 2017), which indicates a synergic relation when there is a greater proximity towards this population (Corrigan, 2016).

As can be seen, the international evidence shows that medical students possess several attitudes towards people affected by a mental illness, which directly impacts in the quality of the cares and attention given to the patients affected by these pathologies (Stefanovics et al., 2016). This is of great importance, since these attitudes generate direct consequences in the affected people's mental health, which can lead to serious repercussions such as suicide (Campo-Arias \& Herazo, 2015). This is why it is important to early know medical student's beliefs and attitudes towards these users and thus identify 
possible negative perceptions and implement actions in order to reduce the stigmatization in this group and its consequences in health care user population (Buechter et al., 2013).

\section{Methodology}

\section{Participants}

The participant population was composed by 12 students from first to fourth year of the medical degree at the Universidad del Desarrollo in Santiago, Chile. 50\% of the participants were women and $50 \%$ were men, all aged between 18 and 24 years old $(M=20.25 ; S D=2.05)$.

As explained before and according to the literature review, there is a difference in respect of participant's gender and age in the attitude towards people affected by mental illness, so it was decided as sampling strategy to divide it into four dimensions. This way, 6 male students and 6 female students were interviewed, where 3 of each group were under 20 years old and 3 were over 20 years old. This was done in order to reach saturation, which is understood as the point where it has been already analyzed a certain diversity of ideas in the field of qualitative research and with each interview or further observation do not appear new elements (Suri, 2011).

\section{Procedure}

The paradigm used in this research corresponds to the constructivist, which allude to the construction of a reality according to the understanding of the participants based on their own lived experiences in their contexts and everyday life helping in the development of subjective senses as of experiences about a situation (Creswell et al., 2007). The methodological design which was carried out this research with corresponds to the denominated "Case Study", where the researcher explores one or more cases over time in order to develop a detailed description and analysis of them, so as to focalize the interest in a study phenomenon and select multiple perspectives (Suri, 2011).

The research project was evaluated and approved by the Undergraduate Research Ethics Committee of The Faculty of Medicine Universidad del Desarrollo and was conducted in accordance with the Declaration of Helsinki (General Assembly of the World Medical Association, 2014) and Singapore (Resnik \& Shamoo, 2011). Moreover, the authorization of the director of Medical School, along with the authorization of the Direction of Student Affairs to carry out that research.

The way the participants were selected was through a convenience sampling, because it allows the researcher to select the desired sampling to collect the necessary information (Etikan et al., 2016).Between the months of June to September 2019 and after the informed consent was signed by the participants, the researcher proceeded to the recording and data collection of the interview using an individual script of semi-structured open questions, described below.

\section{Instruments}

In order to achieve the purposes of the research, the script of semi-structured open questions was developed and adapted for the present study from a previous instrument (Jamshed, 2014), specifically on the basis of the dimensions evaluated in the Community Attitudes Towards Mental Illness scale (CAMI) by Taylor \& Dear (1981). As a result, the following open-ended questions were designed and applied during the interview:

1. What do you think about people with mental illness?

2. Would you make a difference in treating a patient with mental illness?

3. How are people with mental illness discriminated against? 
4. Do you think people with mental illness are more fragile or dependent?

5. Do you think people with mental illness are dangerous or very aggressive?

\section{Data Analysis}

All the information from the semi-structured interviews was turned into written material, then its transcription process was done in order to turn reality into documentary material (Smith \& Firth, 2011). The written material was analyzed through the utilization of thematic content analysis in order to identify and analyze the presence of terminology or concepts from the data gathered, which permits the creation of codes and emerging categories from the participants for every single question that was the focus of research analysis (Braun \& Clarke, 2014). Software Nvivo was employed for the analysis of qualitative data, facilitating the storing, codification, and later data retrieval (Leech \& Onwuegbuzie, 2011).

\section{Results}

A total of 12 semi-structured interviews were done to medical students of first- to fourth-year. Six interviews were done to women students with an average age of 20.75 years old $(S D=2.3)$ and six to male students with an average age of 19.75 years old $(S D=1.8)$. Table 1 summarizes the whole results of the study.

Table 1

Categories of attitudes towards people with mental illness among students according to year of the medical degree and gender

\begin{tabular}{lll}
\hline \multicolumn{1}{c}{ Dimensions } & \multicolumn{1}{c}{ Male students } & \multicolumn{1}{c}{ Female students } \\
\hline First year students & $\begin{array}{l}\text { Tolerance and acceptance attitude } \\
\text { Uncertainty and fear attitude }\end{array}$ & $\begin{array}{l}\text { Indifference and rejection attitude } \\
\text { Empathic and benevolent attitude }\end{array}$ \\
\hline Second year students & Uncertainty and fear attitude & $\begin{array}{l}\text { Frustration attitude } \\
\text { Tolerance and acceptance attitude }\end{array}$ \\
\hline Third year students & $\begin{array}{l}\text { Frustration attitude } \\
\text { Indifference and rejection attitude }\end{array}$ & $\begin{array}{l}\text { Empathic and benevolent attitude } \\
\text { Tolerance and acceptance attitude }\end{array}$ \\
& Uncertainty and fear attitude \\
& Empathic and benevolent attitude & \\
\hline Fourth year students & Tolerance and acceptance attitude & Empathic and benevolent attitude \\
& Uncertainty and fear attitude & Tolerance and acceptance attitude \\
\hline
\end{tabular}

To proceed, the results of the research are shown according to the type of attitude present, which were determined from the emerging categories and based on the reviewed literature:

\section{Empathic and benevolent attitude towards people affected by mental illness}

It is understood as the ability of perceive, share, and understand people's feelings and emotions on the part of medical students, as well as showing affection on someone who has authority or power (Cuff et al., 2016). This is presented in a transversal way in the interviewees, and it is evident in female students of all years, being primarily mentioned the feelings that are generated towards people with mental illness and the willingness to help, as represented in the following quotes from some of the research participants: 
- "Suddenly, I feel sadness because I think why should they be going through this? Ultimately, I think in how difficult is for those people to live, get things done, and anyway they are isolated from society in many aspects since people put them down". (2.1F18)

- "...from the empathy, but not for that reason make them feel worthless, but just understand what they suffer and help them when they need, but it's not about assuming they always need help, do I make myself clear?" (7.3M21)

The interviewees express empathy for the patient when they are isolated and discriminated by society in different aspects, however, this do not mean dismissing them due the fact of being affected by a mental illness.

\section{Frustration attitude towards people affected by mental illness}

It is understood as that attitude where the medical student is unable to meet the postulated needs nor the objectives, mainly in the clinical environment and case management (Neufeld \& Malin, 2019). This code is present from second year and is evident on male students who possess a greater rapprochement in clinical practice as the years of the degree goes, as exemplified and detailed in the following citations:

- "With mental illness is quite different, because it's a very slow process, it's slow and exhausting for the patient as for people who treat it, there could be a relapses, stuffs beyond the disease, the context, the family, the support network that the patient has contribute in their recovery and this is frustrating because oneself want to the patient to recover and don't know what to do to get him better because it's a mental illness that it can't be fixed like a simple surgery." (9.2F20)

The interviewee comments that it is frustrating for the patient as for the professional to treat a mental illness, since different external elements take part in, such as the support network and past experiences.

- "...you have to totally handle your expressions, your movements changes, your voice changes, then you are too focused in trying to not generate problems to patient so you are going to stress out and at the same time between that you must manage to engage the patient and make him understand the treatment and if he doesn't you already have 3 problems, this adds up and even though oneself try to release that stress in emotions you must have a happy and calm face adding up until comes a point where the professional blows up". (5.3M20)

The interviewee explains that is stressful for him to adapt to clinical situation of users, in addition to focus in aspects as the understanding of indications, time management, and the attention towards patients affected by mental illness.

- 'If I was doctor and comes a psychiatric patient, first I don't like the area, I would think that's so tedious, it's a lot of work, it's necessary to know about it, to classify, testing, oneself don't know a lot about the psychiatric disease, it's kind of there aren't many concrete stuff and all of this is too frustrating". (7.3M21)

For the interviewee is frustrating the work that implies dealing with patients affected by mental pathologies, along with the lack of certainty in the comprehension of these diseases.

\section{Indifference and rejection attitude towards people affected by mental illness}

This negative attitude is understood as the lack of constant attention, avoidance, or exclusion of people affected by any mental illness on the part of medical students (Kenny et al., 2018). 
Although this attitude is not common in the analyzed group, it is present in both genders in 2 students of first- and fourth-year of the degree, principally alluding to rejection of dealing or working with someone affected by a mental illness, as evidence in the following citations:

- “... I don't think discrimination is wrong, I mean arbitrarily discriminate is wrong, but discrimination not, for example if I were school principal and I have an appointment with a teacher and I realized that he has (hmm) I don't know, dude, he has bipolar disorder, then is like obvious I wouldn't hire him for teacher position, because it wouldn't be sane for the students and... he must be treated". (1.1F19)

The interviewee refers to rejection towards patients with a mental illness such as bipolar disorder, for not believing that it is convenient that a person with this pathology is appropriate for working, for example, in a school.

"... so, when we're not ready and willing to deal with it (with patients affected by mental pathologies); we immediately rather refer him to another professional and pass the problem to another professional". (5.3M20)

The interviewee refers to rejection when he says that he believes that it is preferable to refer the patient to another professional for several reasons, as not having the knowledge of how deal with it nor having the disposition to handle a patient with this type of pathology.

\section{Uncertainty and fear attitude towards people affected by mental illness}

This code is understood as the lack of conviction or certainty, anxiety sensation on the part of medical students of dealing with people affected by mental illness or handling them (Sweeney et al., 2015). This attitude is presented only in the male students every level in a transversal way, being the main alluded references to be harmed or the unpredictable behavior of the users, such as evidenced in the following citations:

- "Yes, it must be hospitalized some way, because if they compromise their ability of normally socializing, then it's necessary for their health and the people that could affect their behavior, they'd better to be hospitalize". (5.3M20)

Fear is inferred from the interviewee, since he explains that it is necessary to hospitalize a patient if its behavior affects the people around him.

- "Then it would make a difference because if the person is more susceptible to changes of tone and feels it as a more violent, thing than for a healthy person would be totally normal, obviously I have to be more careful with changes of tone, with expressions with him. Then oneself has to take precautions because it's not only a matter of helping the patient, but also of not making things worse for ourselves". (5.3M20)

The interviewee refers to fear and uncertainty in his testimony, since he explains that patients may be more susceptible to react in an unpredictable way to different attitudes of the professional, and therefore be careful with the reactions that the affected person will have.

- 'They must be carefully treated anyway, because oneself doesn't know how they will react, it's like the... at least I that I don't really know hmm [sic] ... oneself treats them from the ignorance, so oneself must have guard". (8.1M19)

Again, fear is inferred from the interviewee because of the reaction the patient may have in certain instances.

- "Perhaps I can't deny that I feel afraid, but it wouldn't be note, but others would be more notorious. It's like be afraid of they can do something and "PAAM!" [sic] They hit you a punch, or grip. Uhm yes, the craziest ones in a way to say it, you can see them more agitated, and it's like they invade a little bit of your personal space, I get scared". (10.4M24) 
The interviewee verbalizes feeling fear, also subsequent to the patient's reaction, referring to a negative attitude by the user, which can end even in a physical aggression.

\section{Tolerance and acceptance attitude towards people affected by mental illness}

This attitude is understood when the medical student socially accepts and respects beliefs of people who are affected by a mental illness (Kim \& Lee, 2018).

It is present in an evident in a transversal way to female students in all years of the degree, and only in 2 male students of first- and fourth- year, being it referred mainly to the equity in the treatment and attention, such as evidenced in the following citations:

- “...it's a super prevalent thing (mental illness), any person on your side can have one and not for this there should be a change in your attitude, a different treatment, etc. Eventually, the rules of the games are the same for everyone". (6.4M23)

The interviewee mentions that mental illnesses are not something external to daily life and the treatment must be equal towards this people.

- "... I think that we all have this... this thought that we are the responsible ones of making the patient feel comfortable and despite it has a mental illness we must offer that secure environment since it's our duty and we must treat them like normal people, because their mental illness does not identify them as a person." (9.2F20)

The citation above reflects the responsibility felt by the interviewee of looking at the patient affected by its mental illness just like any other health user, referring to the fact that disease should not be a limitation on the treatment.

\section{Discussion}

This study suggests that there is a diverse attitude towards mental illness in medical students, which is concordant with what was previously stated by studies of Stefanovics et. al (2016) at international level, where the variety of attitudes that those students can have is evidenced.

One of the main findings of the male medical students is that they have a fear and uncertainty of the harmful behavior that patients affected by psychiatric pathologies may have, being those similar to the negative attitude described on literature in general population (Martin et al., 2007). Nevertheless, the fear of being attacked it has not been described in medical students on qualitative studies at the level of literature, which is interesting to evaluate given the possible research bias in other research, and that can be explained in part by the pressure social desirability in the answers that may skew these findings (Kopera, et al., 2015).

Another present attitudes are empathy and benevolence towards these patients, which is evident on first-year students and in a transversal way to female students. This is similar to what Ewalds-Kvist et al. (2013) had described internationally in their research which shows that in the early stages of formation there is an empathic feeling and need to help on students from the medical area. In that sense, Desai \& Chavda's (2018) research indicates that female students have a more empathetic attitude toward people with mental illness, which is consistent with this study's findings.

Another of the present findings on medical students was a social acceptance and tolerance attitude, in third- and fourth-year students of the degree, and particularly transversal way in female students, which is concordant with the described international literature and what was observed in the research of Poreddi et al. (2014), who mention the existence of an improvement in this attitude as students go through during the university education process, especially in women students (Pascucci et al., 2017). 
A frustration attitude was also discovered on students, which is evidenced inasmuch as they present a greater clinical rapprochement towards patients with psychiatric pathologies, making reference principally to the lack of tools, pathologies comprehension, and scarce recovery of the patients affected by mental health conditions. This finding at international level it has been observed on medical students during their last years of degree, especially in male students (Pascucci et al., 2017), along with the presence of frustration associated to the non-fulfillment of the clinical objectives and also related to the lack of knowledge in deficit areas (Hill et al., 2018).

Within the less common attitudes and reported in two students, there is rejection and indifference, which is evident when one of them point to the negative of hiring people affected by psychiatric conditions. According to the proposed background at international level and in accordance with Corrigan \& Watson's (2002) research, there is a similar rejection in general population, which it has been also mentioned by Schulzed et al. (2007) on research performed on professionals dedicated to mental health regarding the stigma that these patients present on the part of society. Despite this, it is particularly interesting that the rejection present in the testimonies of both medical students has not been described in the national and international literature, which contrary to this finding, states that students in the area of health present attitudes of positive characteristics towards people with mental illness in comparison with the general population (Abolfotouh et al., 2018).

\section{Conclusions}

According to the described findings, it is concluded that through the present investigation it was possible to know and to describe the attitude that the medical students of first- to fourth- year have towards people with mental illness. Among the most relevant findings were found attitudes of fear and uncertainty in the male students in a transversal way towards harmful behavior by patients with mental illnesses, where the feeling of fear of being attacked has not been described in depth at the level of the literature reviewed. The empathic and benevolent attitude is present in an evident way in the first years of the degree and especially in female students, being similar to what has been described at an international level. Another attitude described was social acceptance and tolerance and is observed with greater emphasis in third- and fourth-year medical students, and particularly in woman students, which is concordant with the literature described before. On the other hand, the frustration attitude was one of the findings described in a transversal way with a greater focus on men, which is exacerbated inasmuch as there is a greater clinical rapprochement to patients with psychiatric pathologies. Thus, among the less common attitudes is rejection and indifference, a finding not previously described in depth in the national and international literature. With regard to the knowledge deficit, there is limited literature on the attitude of medical students towards people affected by mental illnesses from a qualitative perspective, as well as little evidence in other student groups, generally focusing on professionals and the general population. In this sense, it is proposed to explore in greater depth the level of knowledge that medical students possess and the associated factors that can influence their attitude, in addition to investigating the impact on attitude and stigma generated by the development of interventions in medical students and other related disciplines.

For the health area, this study takes on vital relevance since it is intended to be a contribution, generating knowledge by allowing a greater understanding of this phenomenon, being possible to extrapolate to different areas of health, and thus to be a tool for faculty and clinical staff in the area of mental health. In that sense, the medical degree possesses a direct and stable contact with psychiatric patients, so studies in this area promote and complement further professional preparation, which in turn represents a number of challenges in the different disciplines in order to promote a positive attitude and 
greater rapprochement on the part of students, professionals, and general population towards people affected by mental illnesses.

Thus, for the health area, these relevant findings should be considered in the different areas, challenging professionals in respect of multidisciplinary work, which considers carrying out promotion and prevention actions in health teams, along with the design and implementation of contact-based educative interventions that promote a decrease of negative behaviors, attitudes, and stigmas towards people affected by psychiatric diseases. This way, one of the challenges in this area is to include investigations that consider the implementation of longitudinal and comparative studies that measure the impact and efficacy of these interventions.

In addition, from this research arise inquiries such us to deeply know the process of attitude's development and behavior on medical students, the influence of familiar factors, and the process of social learning of the peer group that determine that attitude, which generates a direct impact in the results of health and life quality of people affected by mental illnesses.

Among the limitations of the study is the relatively small sample size, so it is not possible to generalize the results. Also, specific characteristics of the participants that may influence the results, such as socio-cultural factors, level of knowledge and approach to mental disorders, were not assessed.

\section{References}

Abolfotouh, M., Almutairi, A., Almutairi, Z., Salam, M., Alhashem, A., Adlan, A., \& Modayfer, O. (2018). Attitudes toward mental illness, mentally ill persons, and help-seeking among the Saudi public and sociodemographic correlates, Psychology Research and Behavior Management, 12, 45-54. https://doi.org/10.2147/PRBM.S191676

Anagnostopoulos, F., \& Hantzi, A. (2011). Familiarity with and social distance from people with mental illness: Testing the mediating effects of prejudiced attitudes. Journal of Community and Applied Social Psychology, 21(5), 451-460. https://doi.org/10.1002/casp.1082

Arens, E., Berger, C., \& Lincoln, T. (2009). Stigmatization of patients with schizophrenia: the influence of university courses on the attitudes of prospective psychologists and doctors. Nervenarzt, 80(3), 329-339. https://doi.org/10.1007/s00115-008-2646-4

Björkman, T., Angelman, T., \& Jönsson, M. (2008). Attitudes towards people with mental illness: a cross-sectional study among nursing staff in psychiatric and somatic care. Scandinavian Journal of Caring Sciences, 22(2), 170-177. https://doi.org/10.1111/j.14716712.2007.00509.x

Braun, V., \& Clarke, V. (2014). What can "thematic analysis" offer health and wellbeing researchers? International Journal of Qualitative Studies on Health and Well-Being, 9, 26152-26153. https://doi.org/10.3402/qhw.v9.26152

Buechter, R., Pieper, D., Ueffing, E., \& Zschorlich, B. (2013). Interventions to reduce experiences of stigma and discrimination of people with mental illness and their caregivers. Cochrane Database of Systematic Reviews, 2, 1-13. https://doi.org/10.1002/14651858.cd010400

Campo-Arias, A., \& Herazo, E. (2015). The stigma-discrimination complex associated with mental disorder as a risk factor for suicide. Revista Colombiana de Psiquiatria, 44(4), 243-250. https://doi.org/10.1016/j.rcp.2015.04.003

Corrigan, P., \& Wassel, A. (2008). Understanding and influencing the stigma of mental illness. Journal of Psychosocial Nursing and Mental Health Services, 46(1), 42-48. https://doi.org/10.3928/02793695-20080101-04

Corrigan, P. W. (2016). Lessons learned from unintended consequences about erasing the stigma of mental illness. World Psychiatry, 15(1), 67-73. https://doi.org/10.1002/wps.20295 
Corrigan, P. W., \& Watson, A. C. (2002). Understanding the impact of stigma on people with mental illness. World psychiatry: Official Journal of the World Psychiatric Association (WPA), 1(1), $16-20$.

Corrigan, P. W., Sokol, K. A., \& Rüsch, N. (2013). The impact of self-stigma and mutual help programs on the quality of life of people with serious mental illnesses. Community Mental Health Journal, 49(1), 1-6. https://doi.org/10.1007/s10597-011-9445-2

Creswell, J., Hanson, W., Clark, V., \& Morales, A. (2007). Qualitative research designs: Selection and implementation. The Counseling Psychologist, 35(2), 236-264. https://doi.org/10.1177/0011000006287390

Cuff, B., Brown, S. J., Taylor, L., \& Howat, D. (2016). Empathy: a review of the concept running head. Emotion Review, 8(2), 144-153. https://doi.org/10.1177/1754073914558466

Desai, N. D., \& Chavda, P. D. (2018). Attitudes of undergraduate medical students toward mental illnesses and psychiatry. Journal of Education and Health Promotion, 7, 50-57. https://doi.org/10.4103/jehp.jehp_87_17

Ebrahimi, H., Namdar, H., \& Vahidi, M. (2012). Mental illness stigma among nurses in psychiatric wards of teaching hospitals in the north-west of Iran. Iranian Journal of Nursing and Midwifery Research, 17(7), 534-538.

Ellemers, N., Spears, R., \& Doosje, B. (2002). Self and social identity. Annual Review of Psychology, 53, 161-186. https://doi.org/10.1146/annurev.psych.53.100901.135228

Etikan, I., Musa, S. A., \& Alkassim, R. S. (2016). Comparison of convenience sampling and purposive sampling. American Journal of Theoretical and Applied Statistics, 5, 1-4. https://doi.org/10.11648/j.ajtas.20160501.11

Ewalds-Kvist, B., Högberg, T., \& Lützén, K. (2013). Impact of gender and age on attitudes towards mental illness in Sweden. Nordic Journal of Psychiatry, 67(5), 360-368. https://doi.org/10.3109/08039488.2012.748827

Funk, M., Drew, N., \& Knapp, M. (2012). Mental health, poverty and development. Journal of Public Mental Health, 11(4), 166-185. https://doi.org/10.1108/17465721211289356

General Assembly of the World Medical Association (2014). World Medical Association Declaration of Helsinki: ethical principles for medical research involving human subjects. The Journal of the American College of Dentists, 81(3), 14-18. https://doi.org/10.1001/jama.2013.281053

Hill, M. R., Goicochea, S., \& Merlo, L. J. (2018). In their own words: stressors facing medical students in the millennial generation. Medical Education Online, 23(1), 1530558-1530567. https://doi.org/10.1080/10872981.2018.1530558

Howard, L., de Salis, I., Tomlin, Z., Thornicroft, G., \& Donovan, J. (2009). Why is recruitment to trials difficult? An investigation into recruitment difficulties in an RCT of supported employment in patients with severe mental illness. Contemporary Clinical Trials, 30(1), 4046. https://doi.org/10.1016/j.cct.2008.07.007

Hsiao, C., Lu, H., \& Tsai, Y. (2015). Factors influencing mental health nurses' attitudes towards people with mental illness. International Journal of Mental Health Nursing, 24(3), 272-280. https://doi.org/10.1111/inm.12129

Jadhav, S., Littlewood, R., Ryder, A., Chakraborty, A., Jain, S., \& Barua, M. (2007). Stigmatization of severe mental illness in India: Against the simple industrialization hypothesis. Indian Journal of Psychiatry, 43(9), 189-194. https://doi.org/10.4103/0019-5545.37320

Jamshed, S. (2014). Qualitative research method-interviewing and observation. Journal of Basic and Clinical Pharmacy, 5(4), 87-88. https://doi.org/10.4103/0976-0105.141942 
Kenny, A., Bizumic, B., \& Griffiths, K. M. (2018). The prejudice towards people with mental illness (PPMI) scale: structure and validity. BMC Psychiatry, 18(1), 293-305. https://doi.org/10.1186/s12888-018-1871-z

Kim, K., \& Lee, Y. M. (2018). Understanding uncertainty in medicine: concepts and implications in medical education. Korean Journal of Medical Education, 30(3), 181-188. https://doi.org/10.3946/kjme.2018.92

Kopera, M., Suszek, H., Bonar, E., Myszka, M., Gmaj, B., Ilgen, M., \& Wojnar, M. (2015). Evaluating explicit and implicit stigma of mental illness in mental health professionals and medical students. Community Mental Health Journal, 51(5), 628-634. https://doi.org/10.1007/s10597014-9796-6

Lam, A. Y., Jorm, A. F., \& Wong, D. F. (2010). Mental health first aid training for the Chinese community in Melbourne, Australia: Effects on knowledge about and attitudes toward people with mental illness. International Journal of Mental Health Systems, 4(1), 18-24. https://doi.org/10.1186/1752-4458-4-18

Leech, N. L., \& Onwuegbuzie, A. J. (2011). Beyond constant comparison qualitative data analysis: Using NVivo. School Psychology Quarterly, 26(1), 70-84. https://doi.org/10.1037/a0022711

Martin, J. K., Pescosolido, B. A., Olafsdottir, S., \& McLeod, J. D. (2007). The construction of fear: Americans' preferences for social distance from children and adolescents with mental health problems. Journal of Health and Social Behavior, 48(1), 50-67. https://doi.org/10.1177/002214650704800104

Navarro, N., \& Triguero, R. (2019). Estigma en los profesionales de la salud mental: una revisión sistemática. Psychol Soc Educ, 11(2), 253-266. https://doi.org/10.25115/psye.v11i2.2268

Neufeld, A., \& Malin, G. (2019). Exploring the relationship between medical student basic psychological need satisfaction, resilience, and well-being: a quantitative study. BMC Medical Education, 19(1), 405-412. https://doi.org/10.1186/s12909-019-1847-9

Ostrow, L., Manderscheid, R., \& Mojtabai, R. (2014). Stigma and difficulty accessing medical care in a sample of adults with serious mental illness. Journal of Health Care for the Poor and Underserved, 25(4), 1956-1965. https://doi.org/10.1353/hpu.2014.0185

Pan American Health Organization. (2016). Regional Mental Health Atlas. PAHO. https://iris.paho.org/handle/10665.2/28451

Pascucci, M., Ventriglio, A., Stella, E., Di Sabatino, D., La Montagna, M., Nicastro, R., Parente, P., De Angelis, A., Pozzi, G., Janiri, L., \& Bellomo, A. (2017). Empathy and attitudes towards mental illness among Italian medical students. International Journal of Culture and Mental Health, 10(2), 174-184. https://doi.org/10.1080/17542863.2016.1276947

Poreddi, V., Thimmaiah, R., \& BadaMath, S. (2017). Medical and nursing students' attitudes toward mental illness: An Indian perspective. Investigación y Educación en Enfermería, 35(1), 8694. https://doi.org/10.17533/udea.iee.v35n1a10

Poreddi, V., Thimmaiah, R., Pashupu, D., Ramachandra, S., \& Badamath, S. (2014). Undergraduate nursing students' attitudes towards mental illness: Implications for specific academic education. Indian Journal of Psychological Medicine, 36(4), 368-372. https://doi.org/10.4103/0253-7176.140701

Resnik, D. B., \& Shamoo, A. E. (2011). The Singapore statement on research integrity. Accountability in Research, 18(2), 71-75. https://doi.org/10.1080/08989621.2011.557296

Salve, H., Goswami, K., Sagar, R., Nongkynrih, B., \& Sreenivas, V. (2013). Perception and attitude towards mental illness in an urban community in South Delhi - A community based study. Indian Journal of Psychological Medicine, 35(2), 154-158. https://doi.org/10.4103/02537176.116244 
Schulze, B. (2007). Stigma and mental health professionals: A review of the evidence on an intricate relationship. International Review of Psychiatry, 19(2), 137-155. https://doi.org/10.1080/09540260701278929

Smith, J., \& Firth, J. (2011). Qualitative data analysis: the framework approach. Nurse Researcher, 18(2), 52-62. https://doi.org/10.7748/nr2011.01.18.2.52.c8284

Stefanovics, E., Rosenheck, R., He, H., Ofori-Atta, A., Cavalcanti, M., \& Chiles, C. (2016). Medical student belief and attitudes toward mental illness across five nations. The Journal of Nervous and Mental Disease, 204(12), 909-915. https://doi.org/10.1097/NMD.0000000000000610

Suri, H. (2011). Purposeful sampling in qualitative research synthesis. Qualitative Research Journal, 11(2), 63-75. https://doi.org/10.3316/qrj1102063

Sweeney, A., Gillard, S., Wykes, T., \& Rose, D. (2015). The role of fear in mental health service users' experiences: a qualitative exploration. Social Psychiatry and Psychiatric Epidemiology, 50(7), 1079-1087. https://doi.org/10.1007/s00127-015-1028-z

Taylor, S. M., \& Dear, M. J. (1981). Scaling community attitudes toward the mentally ill. Schizophrenia Bulletin, 7(2), 225-240. https://doi.org/10.1093/schbul/7.2.225

Too, L. S., Spittal, M. J., Bugeja, L., Reifels, L., Butterworth, P., \& Pirkis, J. (2019). The association between mental disorders and suicide: A systematic review and meta-analysis of record linkage studies. Journal of Affective Disorders, 259, 302-313. https://doi.org/10.1016/j.jad.2019.08.054

Trautmann, S., Rehm, J., \& Wittchen, H. U. (2016). The economic costs of mental disorders: Do our societies react appropriately to the burden of mental disorders? EMBO Reports, 17(9), 12451249. https://doi.org/10.15252/embr.201642951

Vicente, B., Saldivia, S., \& Pihán, R. (2016). Prevalence and gaps today; mental health tomorrow. Acta Bioethica, 22(1), 51-61. https://doi.org/10.4067/s1726-569x2016000100006

Wahl, O., \& Aroesty-Cohen, E. (2010). Attitudes of mental health professionals about mental illness: a review of the recent literature. Journal of Community Psychology, 38(1), 49-62. https://doi.org/10.1002/jcop.20351

Yang, L. H., Valencia, E., Alvarado, R., Link, B., Huynh, N., Nguyen, K., ... Susser, E. (2013). A theoretical and empirical framework for constructing culture-specific stigma instruments for Chile. Cadernos Saúde Coletiva, 21(1), 71-79. https://doi.org/10.1590/S1414462X2013000100011

Yuan, Q., Picco, L., Chang, S., \& Abdin, E. (2017). Attitudes to mental illness among mental health professionals in Singapore and comparisons with the general population. PLoS One, 12(11), 1-14. https://doi.org/10.1371/journal.pone.0187593 